\title{
Investigation on the micromilled surface characterization through replica technology
}

\author{
Baruffi, Federico; Parenti, P.; Cacciatore, F.; Annoni, M.; Tosello, Guido
}

Published in:

Proceedings of the 11th International Conference on Multi-Material Micro Manufacture (4M2016) : co-organised with 10th International Workshop on Microfactories (IWMF2016)

Link to article, DOI:

10.3850/978-981-11-0749-8 726

Publication date:

2016

Document Version

Publisher's PDF, also known as Version of record

Link back to DTU Orbit

Citation (APA):

Baruffi, F., Parenti, P., Cacciatore, F., Annoni, M., \& Tosello, G. (2016). Investigation on the micromilled surface characterization through replica technology. In Proceedings of the 11th International Conference on MultiMaterial Micro Manufacture (4M2016) : co-organised with 10th International Workshop on Microfactories (IWMF2016) (pp. 277-280). Research Publishing Services. https://doi.org/10.3850/978-981-11-0749-8 726

\section{General rights}

Copyright and moral rights for the publications made accessible in the public portal are retained by the authors and/or other copyright owners and it is a condition of accessing publications that users recognise and abide by the legal requirements associated with these rights.

- Users may download and print one copy of any publication from the public portal for the purpose of private study or research.

- You may not further distribute the material or use it for any profit-making activity or commercial gain

- You may freely distribute the URL identifying the publication in the public portal 


\title{
Investigation on the micromilled surface characterization through replica technology
}

\author{
Baruffi F.1,2, Parenti P. ${ }^{2}$, Cacciatore F. ${ }^{2}$, Annoni M. ${ }^{2}$, Tosello G. ${ }^{1}$ \\ ${ }^{1}$ Technical University of Denmark, Department of Mechanical Engineering, \\ Produktionstorvet, Building 427A, 2800 Kgs. Lyngby, Denmark \\ 2 Politecnico di Milano, Department of Mechanical Engineering, via La Masa 1, Milan, Italy
}

\begin{abstract}
Micromilling is one of the most suitable technologies for the direct manufacturing of freeform micro components as well as for the generation of complex geometries typical of micro mould manufacturing. In this context, a detailed knowledge of the surface topography is fundamental to deal with quality control and tolerances to meet the parts functionality. However, in many cases, the reduced accessibility caused by the part complex features (e.g. microcavities, micro-holes, deep-cores) prevents from performing a direct measurement of the surface, using both contact and non-contact techniques. This represents an open issue that, in some cases, can be tackled by adopting the replication technology. The method consists in obtaining the replicated surface and performing its measurement using suitable measuring systems. This paper evaluates the actual performance of a commercial replication product for the indirect measurement of micromilled surfaces, characterized by submicrometer roughness levels. The study assesses the performance of the replication method by measuring the surface roughness (in terms of Sa) of specifically designed micromilled flat surfaces. A 3D confocal optical microscope is employed for the measurements. Two different workpiece materials (AISI 440, annealed and hardened), two different milling conditions (roughing and finishing types) and three replications of each surface are analyzed. The replication resulted suitable for characterizing micromilled surfaces even if it gives an average overestimation in the nanometric level of the Sa parameter.
\end{abstract}

Keywords: Replica Technology, Roughness, Micro Milling, Surface Metrology

1.

\section{Introduction}

Over the last decade, micromilling has become fundamental in satisfying the high requirements of micro components in numerous engineering fields such as electronics, medicine, biotechnology, communications, avionics, etc [1]. Among all the applications, precision mould manufacturing deserves, for its importance, a special mention. Micromilling versatility, relatively high material removal rate and capability of manufacturing 3D geometries make it ideal to be employed in mould manufacturing for high accuracy replication techniques such as micro injection moulding of polymers [2]. After the geometrical accuracy, one of the most important characteristics to look at is the mould surface topography. This is true not only because the texture is mostly transferred to the moulded product but also because it can affect the injection process (e.g. polymer flow, demoulding phases etc.). Therefore, a deep knowledge of it is strictly necessary for optimizing the production performance. Moreover, the ratio between surface area and volume drastically increases in the micro-scale [3], and this calls for an even more accurate analysis of surface topography. When considering micromilled surfaces, numerous phenomena, negligible in its macro counterpart, become significant: ploughing and burrs formation [4] strongly affect the obtained surface texture, as well as cause defects or imperfect geometries. In this context, the surface texture measurement becomes fundamental. The micromilled topography sensibly varies from case to case, but in most applications the achieved roughness ranges from tenths to hundreds of nanometers on both flat and free-form surfaces.

At present, optical instruments are the most versatile and suitable measuring systems capable of characterizing a 3D surface [5]. However, certain features, as for instance micro-holes or micro-cavities, are inaccessible in many cases for an optical lens, preventing from obtaining their direct measurement. Not many solutions exist and one of the most promising ones is the replication method used in conjunction with ultra-high-resolution measurement systems. Surface replication for surface testing is a non-destructive technique that allows reproducing the microstructures of a surface of interest for consequent indirect examination using different inspection methods [6].

In a very recent study [7], Goodall et al. investigated the replication accuracy of various silicon based replication media by analysing quantitative texture parameters. In particular, they explained how the main polymer characteristic that influences the replica fidelity is viscosity. Usually, low viscosity media replicate a surface more accurately than high viscosity media.

Gasparin et al. [8] studied the surface texture replication performance of three polymers. Two calibrated roughness standards were employed as masters for the replica, and a replication degree up to $96 \%$ was achieved. Since the nominal surface roughness of the measured samples was around 500 $\mathrm{nm}$, the authors' considerations cannot be extended to micromilled surfaces, which are usually smoother.

The use of replica technique has been tested also 
to evaluate the wear rate of $\mathrm{TiN}$ coated injection moulding nickel tool [9], proving to be suitable for inspection purposes. However, at present, the literature still lacks studies focused on the performance verification of a replica procedure applied on micromilled surfaces.

The aim of this paper is to evaluate the performance of a commercial silicone replica (RepliSet Struers $\left.{ }^{\circledR}\right)$ in the indirect measurements of micromilled surfaces of mould steels. The experimental setup, along with the measurement strategy, is presented in Section 2. Section 3 presents the results, while a final discussion follows in Section 4.

\section{Materials and methods}

Different benchmark surfaces, consisting in both micro-roughed and micro-finished surfaces obtained by varying the radial depth of cut, have been machined. The selected material is the AISI 440 in both annealed (AISI $440 \mathrm{~A}$, hardness $=18 \mathrm{HRC}$ ) and hardened (AISI $440 \mathrm{H}$, hardness $=60 \mathrm{HRC}$ ) conditions, representing a reference choice for mould manufacturing. The two materials are expected to produce different surface topographiy in relation to the material characteristics (mainly: hardness, grain size and specific cutting force).

\subsection{Specimens and cutting process design}

The surface design is a key step in the evaluation of the replication method since micromilled surfaces have different characteristics based on the adopted mill type, milling parameters and milling strategy. In particular, three types of micromilled surfaces have been produced on the two materials. A coated WC Round End Mill (2-flutes, diameter $=1 \mathrm{~mm}$, corner radius $=0.1 \mathrm{~mm}$ and cutting edge radius $=6 \mu \mathrm{m}$ ) was used in the tests on an ultra-high precision KERN Evo micro machining centre. The cutting parameters are summarized in Table 1.

Table 1: Cutting parameters.

\begin{tabular}{cccc}
\hline $\begin{array}{c}\text { Reference } \\
\text { Surface }\end{array}$ & S1 & S2 & S3 \\
\hline$a_{\mathrm{e}} / D_{\mathrm{c}}[\%]$ & $\begin{array}{c}100 \% \\
\text { (full slot) }\end{array}$ & $\begin{array}{c}30 \% \\
\text { (overlapped) }\end{array}$ & $\begin{array}{c}30 \% \\
\text { (finished) }\end{array}$ \\
Tool & REM & $\varnothing 1 \mathrm{~mm}(C R=0.1 \mathrm{~mm})$ \\
$a_{\mathrm{p}}[\mu \mathrm{m}]$ & & 50 \\
$v_{\mathrm{c}}[\mathrm{m} / \mathrm{min}]$ & & 100 \\
$f_{\mathrm{z}}[\mu \mathrm{m}]$ & & 12.5 \\
Strategy & \multicolumn{2}{c}{ Longitudinal parallel downmilling } \\
\hline
\end{tabular}

The first surface, named S1, was machined using a full slot machining (i.e. with radial depth of cut $a_{e}$ equal to $1 \mathrm{~mm}$ ). The other two surfaces were obtained by imposing a $30 \%$ radial depth of cut. In particular, S2 corresponds to the overlapped surface area, over which the tool moves on subsequent passes, while S3 identifies the last mill pass, which is not overlapped (Fig.1). The feed per tooth $f_{z}$ was set at the lowest limit for the selected mill.

The choice of producing these particular surfaces lies in the fact that S1 conditions are typical of a roughing operations (e.g. during pocket milling), while S2 and S3 ones are typical of finishing operations where the final surface topography and appearance are generated. By doing this, the fidelity of the silicone replicas is tested on the steps of a hypothetical mould manufacturing procedure. In order to avoid the onset of chatter conditions, which can lead to nonrepresentative surface generation, the axial depth of cut $a_{p}$ has been limited to $50 \mu \mathrm{m}$ for all the tests. Runout of the mill was also measured obtaining a value of $3 \mu \mathrm{m}$. The same mill was used for machining all the samples in order to incorporate the effect of tool wear on surface generation (even if a very limited amount of material was removed).

Each material specimen has been machined obtaining three surfaces, as depicted in Fig. 1. Two replicates for each surface type have been generated, resulting in 6 surfaces per material. As expected, the surfaces appear smooth but with different characteristic patterns.

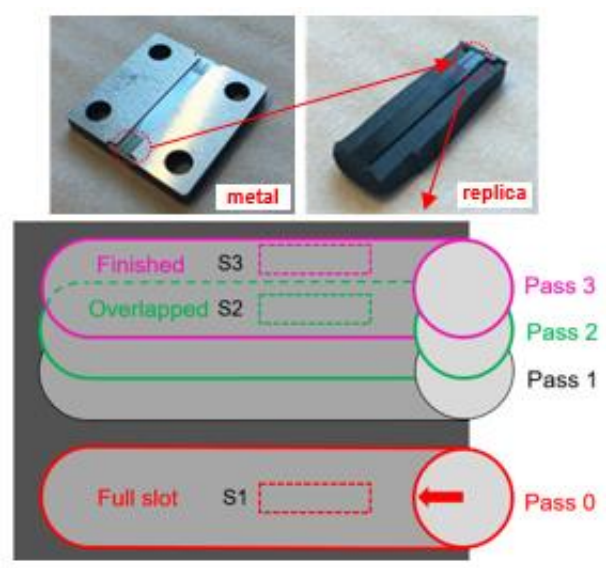

Fig. 1: Micromilled AISI $440 \mathrm{H}$ and its replica.

\subsection{Replication procedure}

After machining, the surfaces were cleaned from metal debris and dirty particles by using an ultrasonic cleaning bath and then blown with filtered chilled air. The black two-component silicone rubber was then poured using the appropriate dispensing gun and following the guidelines suggested by the supplier. After solidification, the parts are carefully peeled off and prepared for the measurement, avoiding any additional contamination of the samples. The pouring procedure is performed three times for each surface, resulting in three silicone replications for each micromilled surface. Thus, a total number of 18 silicone surfaces were obtained for each material.

\subsection{Measuring methodology}

The measurements were carried out using a 3D confocal microscope (MarSurf CWM 100 from Mahr). A dedicated post-processing metrology software (MountainsMap $®$ from Digital Surf) was employed for the analysis of the measurements. The confocal principle has been selected since it is one of the most suitable for surface roughness measurements at nano-scale [5]. A rectangular area of $1 \mathrm{~mm} \times 0.2 \mathrm{~mm}$ has been acquired for each surface with a $100 \times$ optical lens (numerical aperture $=0.9$ and working distance $=$ $1 \mathrm{~mm}$, vertical resolution $=1 \mathrm{~nm}$ ). A stitching operation 
(with 9 images) was automatically performed for acquiring the all surface extension. The position of the $\mathrm{S} 1, \mathrm{~S} 2$ and S3 surfaces was defined with respect to a fixed planar reference position univocally identified on the samples. Fig. 2 depicts the surface topographies belonging to a metal and replicated specimen.

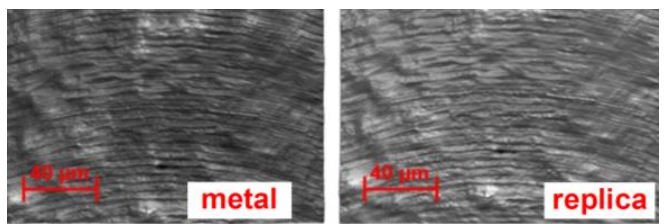

Fig. 2: Acquired Surface topography of the metal and replica specimen (AISI $440 \mathrm{H}$, surface $\mathrm{S} 1$, sample 1).

Once the points clouds were acquired, a form removal fitting was applied on the data. A peakremoval masking was also applied to clean some limited number of spikes on the replica surfaces in order to exclude them from the quantitative roughness analysis. Due to their characteristics, these sharp spikes seemed to be optical artifacts, but in any case, they were distributed on all the replicates surfaces in a very limited number. Finally, the comparison between the master and the silicone replicas was performed based on surface indicators computed for each surface.

An open topic for metrology and process engineering is to find proper surface indicators for defining the functionality of the part [5]. For instance, as regards micro moulds, which are usually produced by micromilling, no common rules exist for evaluating and characterizing the surfaces. In this preliminary evaluation, the Arithmetical Mean Height (Sa) surface parameter is computed according to the general ISO 25178-2 standard [10], to provide an average information of the surface roughness.

Since the aim of the work is to perform a comparison between the direct and indirect measurement procedures, a preliminary analysis was carried out on the repeatability of the measurement chain. In particular, the analysis considered 20 repeated measurements, performed on the same areas of each single metal and replica specimens. The reference position was reached before each one of the repeated measurements in order to evaluate also the uncertainty contribution related to the instrument positioning on the selected area.

The standard deviation of the results was utilized to characterize the repeatability. Finally, an expanded uncertainty (coverage factor $k$ equal to 2 corresponding to a confidence level of about $95 \%$ ) of $5 \mathrm{~nm}$ has been calculated for Sa on both metal and polymer measurements.
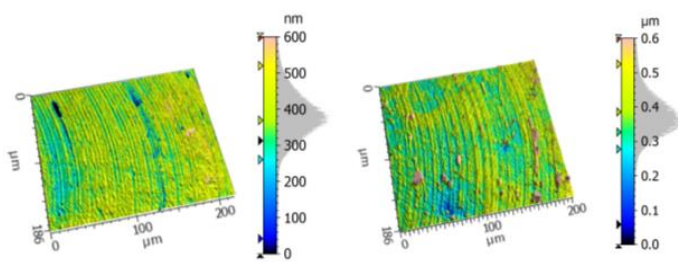

Fig. 3: Measured Surface topography: metal (left) and replica (right) samples (AISI $440 \mathrm{H}$, surface S1, sample 1).

\section{Results and discussions}

\subsection{Comparison between direct and replicated measure}

By analysing the measurements, it turns out that the silicone material seems able to qualitatively replicate the surface texture, even in its finest details. The surface micro-grooves created by the mill passes were reproduced with good fidelity, as shown in Fig. 3. A quantitative analysis based on the $S a$ parameter is presented in Fig. 4.

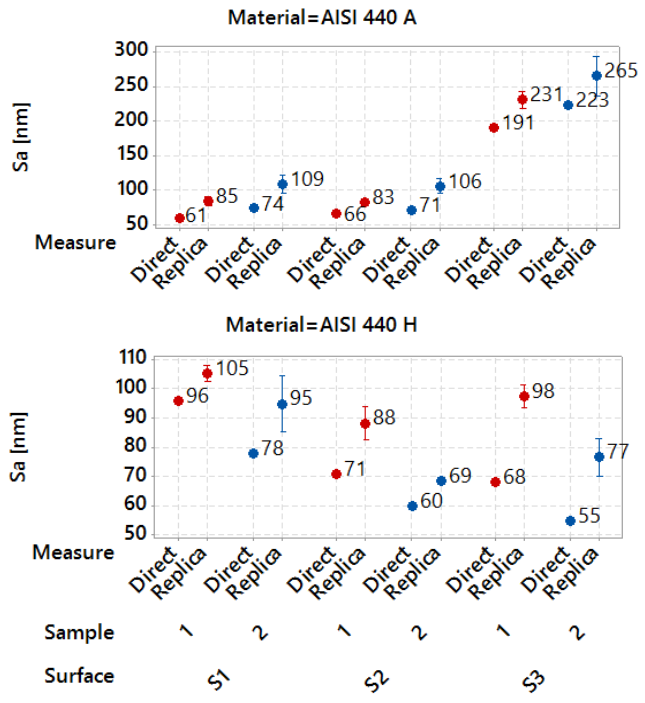

Fig. 4: Interval plot of Sa for Sample 1 and 2.

The AISI 440 annealed material produced S1 and S2 surfaces with similar Sa values in the order of 100 $\mathrm{nm}$, while gives a S3 with significantly higher value (around $200 \mathrm{~nm}$ ). This is somehow in contrast with the expectations since S3 was machined with lowest radial depth of cut, as usual in finishing operations. This particular behaviour was due to the ploughed marks on the surface caused by the soft characteristic and surface elastic recovery tendency of the annealed material. The presence of ploughed marks in both metal and replicated surface acquisitions is shown in Fig. 5. This phenomenon also increased the dispersion of the S3 surfaces with respect to S1 and S2. On the other hand, AISI 440 hardened presents more regular surfaces with no ploughed marks, followed by a decreasing Sa values when moving from the full slot surface (S1) to the other ones (S2 and S3) for both sample 1 and 2 .
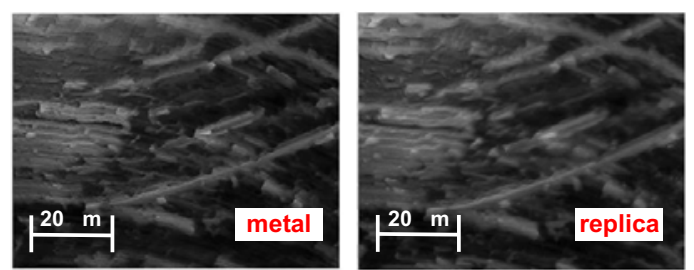

Fig. 5: Detail of ploughed marks on metal and replica surface (AISI 440 A, surface S3, sample 2). 
A certain Sa variability is observed between direct measurements of sample 1 and sample 2. This variability is due to the micromilling process itself, since the surfaces belonging to the two samples were machined with the same cutting parameters.

When comparing direct and indirect measurements, a Sa overestimation is observed in all the tests. This is probably caused by the manual removal of the replica from the micromilled master. Moreover, Sa values vary among the three silicone replications, meaning that a certain variability of the replication procedure also exists.

Table 2 summarizes the numerical results of the direct and indirect measurements. In particular, the mean value and coefficient of variation CoV (defined as the ratio between standard deviation and mean values) of the three silicone replications are shown. In addition to this, the deviation between direct and replica measurements was evaluated by means of a percentage error Err\%, defined as:

$$
E r r_{\%}=\frac{S a_{\text {replica }}-\text { Sa } a_{\text {direct }}}{S a_{\text {direct }}} \cdot 100
$$

The coefficient of variation ranges between $2 \%$ and $13 \%$, meaning that certain variability in the replication procedure exists.

Generally, the replica samples provided an overestimation of Sa parameter. The percentage error ranges between $+10 \%$ and $+44 \%$ for the hardened steel and between $+19 \%$ and $+50 \%$ for the annealed one, with average values of $+26 \%$ and $+34 \%$, respectively. The standard deviation of the error is for both cases equal to $13 \%$ meaning that the overestimation is not systematic. On the one hand, the maximum observed Sa difference is $42 \mathrm{~nm}$, a value which is significantly higher than the measurement repeatability $(5 \mathrm{~nm})$, confirming a limited performance of the replication method. On the other hand, the maximum discrepancy is comparable to the pure variation of the micromilling process for passes executed with same cutting conditions.

Table 2: Sa, CoV and Err\% results.

\begin{tabular}{lccc}
\hline $\begin{array}{l}\text { Material/ Surface/ } \\
\text { Replication }\end{array}$ & $\begin{array}{c}\text { Mean } \\
\text { [nm] }\end{array}$ & CoV & Err\% \\
\hline $\mathrm{AISI} 440 \mathrm{H} / \mathrm{S} 1 / 1$ & 105 & $3 \%$ & $10 \%$ \\
$\mathrm{AISI} 440 \mathrm{H} / \mathrm{S} 2 / 1$ & 88 & $8 \%$ & $24 \%$ \\
$\mathrm{AISI} 440 \mathrm{H} / \mathrm{S} 3 / 1$ & 98 & $5 \%$ & $44 \%$ \\
$\mathrm{AISI} 440 \mathrm{H} / \mathrm{S} 1 / 2$ & 95 & $12 \%$ & $22 \%$ \\
$\mathrm{AISI} 440 \mathrm{H} / \mathrm{S} 2 / 2$ & 69 & $2 \%$ & $14 \%$ \\
$\mathrm{AISI} 440 \mathrm{H} / \mathrm{S} 3 / 2$ & 77 & $10 \%$ & $39 \%$ \\
\hline $\mathrm{AISI} 440 \mathrm{~A} / \mathrm{S} 1 / 1$ & 85 & $8 \%$ & $39 \%$ \\
$\mathrm{AISI} 440 \mathrm{~A} / \mathrm{S} 2 / 1$ & 83 & $7 \%$ & $25 \%$ \\
$\mathrm{AISI} 440 \mathrm{~A} / \mathrm{S} 3 / 1$ & 231 & $6 \%$ & $21 \%$ \\
$\mathrm{AISI} 440 \mathrm{~A} / \mathrm{S} 1 / 2$ & 109 & $13 \%$ & $47 \%$ \\
$\mathrm{AISI} 440 \mathrm{~A} / \mathrm{S} 2 / 2$ & 106 & $11 \%$ & $50 \%$ \\
$\mathrm{AISI} 440 \mathrm{~A} / \mathrm{S} 3 / 2$ & 265 & $13 \%$ & $19 \%$ \\
\hline
\end{tabular}

\section{Conclusions}

The characterization of micromilled surfaces through replica technology has been investigated in this work. Three surfaces were designed and produced on AISI 440 in both annealed and hardened state with roughness that ranges from $\mathrm{Sa}=55 \mathrm{~nm}$ to $\mathrm{Sa}=225 \mathrm{~nm}$. A commercial silicone rubber was used as replication material and both the original and replicated surfaces were acquired by means of a confocal microscope and then processed.

The comparison showed generally larger Sa on the replicated surfaces with respect to the original metal ones. This error, probably caused by the manual removal of the replicated silicone samples, was higher in the annealed material case. An error variability, equal for both the materials, exists, meaning that the silicone did not show a constant Sa overestimation of the metal samples.

Future studies will be devoted to investigate the surface replication performance on more complex geometries such as tilted and free-form surfaces, micro-holes, burrs or high-aspect ratio features. The performance investigation will be extended to other surface topography parameters, and to geometrical as well as dimensional replication capability. Furthermore, an additional step would be to perform an uncertainty quantification of the method following the suggested rules of ISO 15530-3, even though a representative calibration specimen should be defined and carried out for the micromilling case.

\section{References}

[1] X. Liu et al., The Mechanics of Machining at the Microscale: Assessment of the Current State of the Science, J. of Manuf. Sc. and Eng., 126(4):666, 2004.

[2] G. Bissacco et al., Micromilling of hardened tool steel for mould making applications, J. of Mat. Process. Tech., 167(2-3):201-207, 2005.

[3] X. Liu et al., Model-Based Analysis of the Surface Generation in Microendmilling-Part I: Model Development, J. of Manuf. Sc. and Eng., 129(3):453, 2007.

[4] H. Weule et al., Micro-Cutting of Steel to Meet New Requirements in Miniaturization, CIRP Annals - Manu. Tech., 50(1):61-64, 2001.

[5] R. K. Leach, Optical measurement of surface topography, Springer, Berlin, 2011.

[6] H. N. Hansen et al., Replication of micro and nano surface geometries, CIRP Annals - Manu. Tech., 695714, 2011.

[7] R. H. Goodall et al., Accuracy and precision of silicon based impression media for quantitative areal texture analysis, Scientific Reports, 2015; 5:10800.

[8] S. Gasparin et al., Traceable surface characterization using replica moulding technology, 13th International Conference on Metrology and Properties of Engineering Surfaces, 310-315, 2011.

[9] G. Tosello et al., Surface wear of TiN coated nickel tool during the injection molding of polymer micro Fresnel lens, CIRP Annals - Manu Tech., 535-538, 2012.

[10] ISO 25178: Geometric Product Specifications (GPS) - Surface texture: areal. 